\title{
The Evolution of Stress and Strain around the Bayan Har Block in the Tibetan Plateau
}

\author{
Yujun Sun, Taoyuan Fan, Chunjing Zhou, and Zhonghai Wu \\ Institute of Geomechanics, Chinese Academy of Geological Sciences, Beijing 100081, China \\ Correspondence should be addressed to Yujun Sun; sunyujunabc@163.com
}

Received 24 June 2015; Accepted 3 November 2015

Academic Editor: Youshun Sun

Copyright (C) 2015 Yujun Sun et al. This is an open access article distributed under the Creative Commons Attribution License, which permits unrestricted use, distribution, and reproduction in any medium, provided the original work is properly cited.

With the constraint of GPS observation, the tectonic deformation of the Bayan Har block and its periphery faults is investigated based on an elastoplastic plane-stress finite element model. The results show that the elastic model cannot explain the current GPS observation in the Bayan Har block. When East Kunlun fault and Yushu-Xianshuihe fault are under plastic yield state or high strain localization, the calculated velocities fit well with the observation values. It indicates that most of the current shear deformations or strain localizations are absorbed by these two large strike-slip faults. In addition, if the recurrence intervals of large earthquakes are used to limit the relative yield strength of major faults, the order of entering the plastic yield state of the major faults around Bayan Har block is as follows. The first faults to enter the yield state are Yushu-Xianshuihe faults and the middle segment of East Kunlun faults. Then, Margaichaka-RolaKangri faults (Mani segment) and Heishibeihu faults would enter the yield state. The last faults to enter the yield state are the eastern segment of East Kunlun faults and Longmenshan faults, respectively. These results help us to understand the slip properties of faults around the southeastward moving Bayan Har block.

\section{Introduction}

The Tibetan Plateau is the main seismic active area in China. From the south to the north, it is composed of the Himalayan block, Lasha block, Qiangtang block, Hoh Xil-Bayan Har block, Qaidam block, and Qilian Shan block. The Bayan Har block is located in the northern Tibetan Plateau $[1,2]$. Its boundary faults include the Kunlun fault in the north, ManiYushu-Xianshuihe fault in the south, and Longmen Shan in the east $[3,4]$. A series of strong earthquakes have occurred around the Bayan Har block in the Tibetan Plateau since 1997, including Mani earthquake (Mw7.5 on November, 8, 1997 UTC) in Xinjiang province along the Mani fault [5], Kunlun Shan earthquake (Mw7.8 on November, 14, 2001 UTC) in Qinghai province along the Kunlun Shan fault [6-8], Yutian earthquakes (Mw7.1 on March, 20, 2008 UTC and Mw6.9 on February, 12, 2014 UTC) in Xinjiang province along the Altyn Tagh fault [9-11], Wenchuan earthquake (Mw7.9 on May, 12, 2008 UTC) in Sichuan province along Longmen Shan fault [12-14], Yushu earthquake (Mw6.9 on April, 13,
2010 UTC) in Qinghai province along Yushu-Xianshuihe fault $[15,16]$, and Lushan earthquake (Mw6.6 on April 20, 2013 UTC) $[17,18]$. These earthquakes have composed the main seismic activity zone in the Tibetan Plateau in the past decades years [3]. The study of the Coulomb stress among strong earthquakes around the Bayan Har block suggested that it was limited to the fault activity caused by the strong earthquakes. The maximum static Coulomb stress change triggered by the large earthquakes was around $0.01 \mathrm{MPa}[19$, 20]. Focal mechanism of these earthquakes implied that the Bayan Har block has been moving southeastward (Figure 1). Yutian earthquake is caused by a normal fault, which implied extension setting $[21,22]$. Wenchuan earthquake indicated the intense activation of Longmen Shan thrust-fold belt, which is a typical compressive tectonic environment [23-25]. Kunlun Shan earthquake in the north of the block and Yushu earthquake in the south of the block suggested the strike slip of Kunlun Shan fault and Yushu-Xianshuihe fault [26-28]. Thus, what is the relation between these strong earthquakes and the movement of Bayan Har block? Solving this issue 


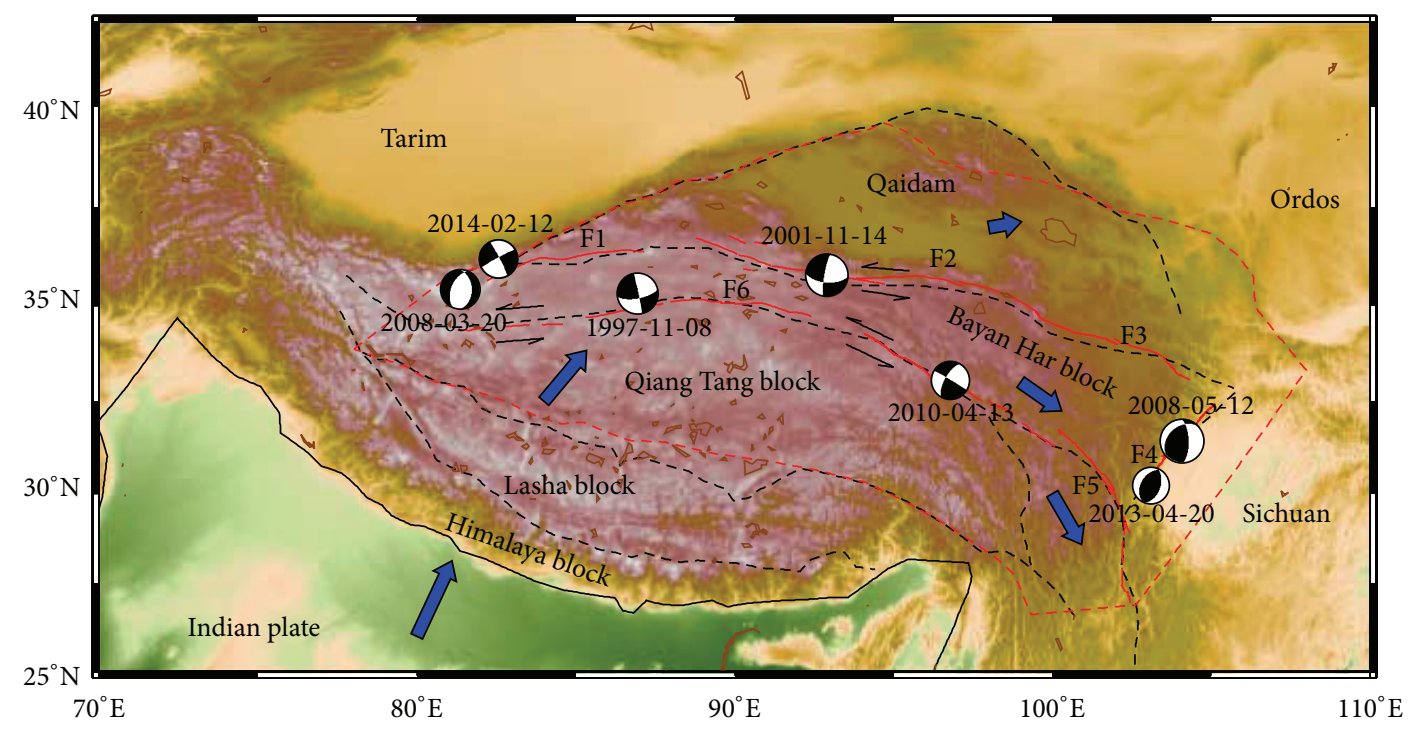

FIGURE 1: Tectonic setting and distribution of recent large earthquakes around Bayan Har block. Mechanisms of earthquakes come from Harvard CMT catalogue (http://www.globalcmt.org/CMTsearch.html). The blue arrows show the movement of block in the Tibetan Plateau according to GPS observation. Red solid lines indicate the major active faults around Bayan Har block [3, 12, 43]. F1: Heishibeihu fault; F2: the middle segment of East Kunlun fault; F3: eastern segment of East Kunlun fault (Maqu-Heye segment); F4: Longmen Shan fault; F5: YushuXianshuihe-Anninghe fault; F6: Margaichaka-RolaKangri faults. The black dashed lines show the boundary of different block in the Tibetan Plateau. The red dashed lines show the area of the finite element model (Figure 2).

will help us to understand the relation between the block movement and occurrence of strong earthquakes around it.

To describe the large-scale and long-term deformation, the continental lithosphere is regarded as a continuum, obeying a Newtonian or a power law rheology [29-31]. However, elastic constitutive equations are usually used to study the short-term deformation of the crust or lithosphere [32, 33]. In plate interiors, deep faults always play an important role during the lithospheric deformation [34, 35]. For instance, the slip and rupture of faults are elastoplastic deformation process. The recurrence of a large earthquake gets to be more than 1000 years. The recurrence of Wenchuan earthquake is estimated to be 2000-6000 years [14]. Thus, elastoplastic rheology with the continuous assumption is adopted in this study, which is effective and convenient to consider the effect of strain localization which is equivalent to the effect of faults [36-40]. Large faults always control the overall movement of the block. Previous studies suggested that large active faults also control the uplift and expansion of the Tibetan Plateau [35, 41, 42]. The slip of faults generally obeys the plastic deformation. However, the strong blocks present rigid or elastic features. Thus, the overall movement of blocks and its peripheral faults should be treated differently in the numerical study. GPS observation is one of the most direct reflection for the short-term tectonic active [33]. It can be used as the boundary conditions in our numerical model.

In this study, based on the GPS observation, we constructed a plane-stress numerical model to investigate the evolution of stress and strain around the Bayan Har block. In this process, we try to investigate the relation between the movement of block and occurrence of strong earthquakes.

\section{Numerical Model}

2.1. Numerical Equation. Faults activities present stick-slip characteristic [44]. In this study, we give high yield strength for the blocks and low yield strength for the faults. Thus, the faults would get to the plastic state firstly under the same increasing stress. High strain rate would be localized along the faults, which causes large slip and stress drop. Corresponding to the seismic activity, large slip or decrease of stress implies the occurrence of earthquake. In this study, a plane-stress model is adopted to study the deformation of block and its surrounding faults. For the plane-stress,

$$
\begin{aligned}
\sigma_{x z} & =\sigma_{y z}=\sigma_{z z}=0, \\
\varepsilon_{z z} & =\frac{-v}{1-v}\left(\varepsilon_{x x}+\varepsilon_{y y}\right),
\end{aligned}
$$

where $v$ is Poisson's ratio, $\sigma_{z z}$ is the normal stress with $z$ direction, and $\sigma_{x z}$ and $\sigma_{y z}$ are two components of shear stresses with $z$ direction. $\varepsilon_{z z}$ is the normal strain with $z$ direction, and $\varepsilon_{x x}$ and $\varepsilon_{y y}$ are two components of shear strains with $z$ direction.

The constitutive equations in this study are the incremental relation between strain $\varepsilon$ and stress $\sigma$ [45]. In the Cartesian coordinate system, the constitutive equations can be expressed as

$$
\{d \sigma\}=\left[D_{\mathrm{ep}}\right]\{d \varepsilon\}
$$

where

$$
\begin{aligned}
{\left[D_{\mathrm{ep}}\right] } & =\left[D_{\mathrm{e}}\right]-\left[D_{\mathrm{p}}\right], \\
\{d \varepsilon\} & =\left\{d \varepsilon^{\mathrm{e}}\right\}+\left\{d \varepsilon^{\mathrm{p}}\right\} .
\end{aligned}
$$




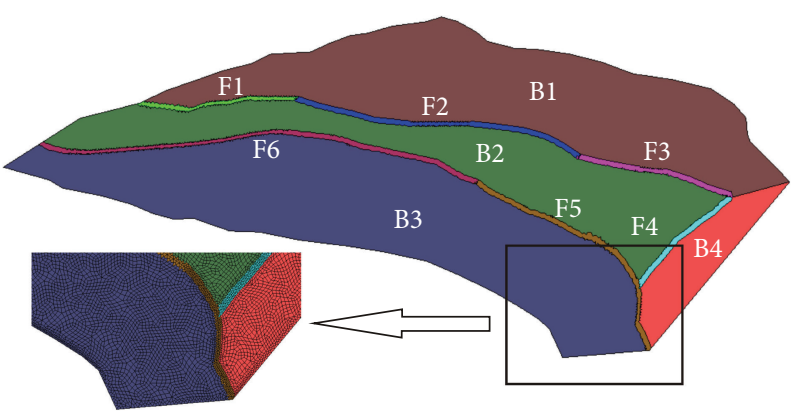

Figure 2: Finite element model used in this study. Different colors in the model show the blocks and faults around Bayan Har block. B1: Qaidam-Qilian Shan block; B2: Bayan Har block; B3: Qiangtang block; B4: Sichuan basin. F1-F6 indicate the major faults (Figure 1). The enlarge region shows the grid mesh of finite element model.

The terms in (3) are expressed as

$$
\left[D_{\mathrm{e}}\right]=\frac{E}{\left(1-v^{2}\right)}\left[\begin{array}{ccc}
1 & v & 0 \\
v & 1 & 0 \\
0 & 0 & \frac{1-v}{2}
\end{array}\right],
$$

$$
\left[D_{\mathrm{p}}\right]
$$

$$
\begin{aligned}
& =\frac{\left[D_{\mathrm{e}}\right]\{\partial F / \partial\{\sigma\}\}\{\partial F / \partial\{\sigma\}\}^{T}\left[D_{\mathrm{e}}\right]}{\{\partial F / \partial\{\sigma\}\}^{T}\left[D_{\mathrm{e}}\right]\{\partial F / \partial\{\sigma\}\}-(\partial F / \partial \kappa)\left\{\partial \kappa / \partial\left\{\mathcal{E}^{\mathrm{p}}\right\}\right\}^{T}\{\partial F / \partial\{\sigma\}\}} \\
& \{d \sigma\}=\left\{\begin{array}{lll}
d \sigma_{x x} & d \sigma_{y y} & d \sigma_{x y}
\end{array}\right\}^{T}, \\
& \{d \varepsilon\}=\left\{\begin{array}{lll}
d \varepsilon_{x x} & d \varepsilon_{y y} & d \varepsilon_{x y}
\end{array}\right\}^{T}, \\
& \left\{d \varepsilon^{\mathrm{e}}\right\}=\left\{\begin{array}{lll}
d \varepsilon_{x x}^{\mathrm{e}} & d \varepsilon_{y y}^{\mathrm{e}} & d \varepsilon_{x y}^{\mathrm{e}}
\end{array}\right\}^{T}, \\
& \left\{d \varepsilon^{\mathrm{p}}\right\}=\left\{\begin{array}{lll}
d \varepsilon_{x x}^{\mathrm{p}} & d \varepsilon_{y y}^{\mathrm{p}} & d \varepsilon_{x y}^{\mathrm{p}}
\end{array}\right\}^{T} .
\end{aligned}
$$

$\left[D_{\mathrm{e}}\right]$ and $\left[D_{\mathrm{p}}\right]$ are the elastic and plastic stiff matrixes, respectively. $\left[D_{\mathrm{ep}}\right]$ is the elastoplastic stiff matrix. $F$ is the yield function. $\mathcal{K}$ is the parameter indicating the loading history, which can be taken as the plastic work $W_{\mathrm{p}}$ or the accumulated plastic strain $\varepsilon_{\mathrm{p}} \cdot\left\{d \varepsilon^{\mathrm{e}}\right\}$ and $\left\{d \varepsilon^{\mathrm{p}}\right\}$ are the elastic and plastic strain increments, respectively. $\{d \varepsilon\}$ is the total strain increment. The same definition is used for the stress and the yield function. $E$ and $v$ are Young's modulus and Poisson's ratio, respectively. Superscript (e) indicates the elastic strain increment and subscript (p) indicates the plastic strain increment. satisfies

The yield function, or can be called loading function,

$$
F \begin{cases}<0: & \text { elastic state } \\ =0: & \text { plastic state }\end{cases}
$$

Drucker-Prager yield criterion is used in this calculation:

$$
F\left(I_{1}, J_{2}\right)=\alpha I_{1}+\sqrt{J_{2}}-H .
$$

$I_{1}$ is the first invariant of stress tensor and $J_{2}$ is the second invariant of deviatoric stress tensor.
For the plane-stress state,

$$
\begin{aligned}
& I_{1}=\sigma_{x x}+\sigma_{y y}, \\
& J_{2}=\frac{1}{6}\left[\left(\sigma_{x x}-\sigma_{y y}\right)^{2}+\sigma_{x x}^{2}+\sigma_{y y}^{2}\right]+\sigma_{x y}^{2}
\end{aligned}
$$

where $\sigma_{x x}, \sigma_{y y}$, and $\sigma_{x y}$ present the three independent components of stress in the Cartesian coordinate system.

$\alpha$ and $H$ denote the material parameters, which can be expressed as

$$
\begin{gathered}
\alpha=\frac{2 \sin \phi}{\sqrt{3}(3+\sin \phi)}, \\
H=\frac{6 c \cos \phi}{\sqrt{3}(3+\sin \phi)},
\end{gathered}
$$

where $c$ and $\phi$ are cohesion and angle of internal friction, respectively.

2.2. Finite Element Mesh and Boundary Conditions. The finite element model covers the whole Bayan Har block and its peripheral blocks and faults. The boundaries of blocks are regarded as faults, which have low yield strength. To facilitate the establishment of the numerical model, the faults around the Bayan Har block are approximately divided into 6 sections (Figure 2). The total number of quadrilateral elements and nodes are 32397 and 32959, respectively. The boundary conditions are imposed with the recent GPS observation [46-48]. We assume that the GPS velocity is not changed within the calculation time. According to the incremental method for elastoplasticity, an annual displacement from the GPS observation is regarded as an incremental time step. In the given calculation time, the final strain or stress is the accumulation of incremental strain or stress. In the elastic state, the strain and stress are having a linear relationship. However, if the deformation gets to the plastic state, the accumulation of strain and stress presents strong nonlinear relationship.

2.3. Model Design and Parameters. The GPS data used in this study is from 1991 to $2005[46,48,49]$. Based on the constraint 
TABLE 1: Cases and material parameters.

\begin{tabular}{lccccc}
\hline & Cases & $E(\mathrm{GPa})$ & $v$ & $\phi($ degree $)$ & $c(\mathrm{MPa})$ \\
\hline \multirow{2}{*}{ Case 1 } & Blocks & 82.5 & 0.25 & 11 & 100.0 \\
& Faults & 82.5 & 0.25 & 11 & 10.0 \\
\hline \multirow{2}{*}{ Case 2 } & Blocks & 82.5 & 0.25 & 11 & 100.0 \\
& F5 & 82.5 & 0.25 & 11 & 1.0 \\
& Other faults & 82.5 & 0.25 & 11 & 10.0 \\
\hline \multirow{4}{*}{ Case 3 } & Blocks & 82.5 & 0.25 & 11 & 100.0 \\
& F2, F5 & 82.5 & 0.25 & 11 & 1.0 \\
& Other faults & 82.5 & 0.25 & 11 & 10.0 \\
\hline \multirow{5}{*}{ Case 4 } & Blocks & 82.5 & 0.25 & 11 & 100.0 \\
& F2, F4, and F5 & 82.5 & 0.25 & 11 & 1.0 \\
& Other faults & 82.5 & 0.25 & 11 & 10.0 \\
\hline \multirow{5}{*}{ Case 5 } & Blocks & 82.5 & 0.25 & 11 & 100.0 \\
& F2, F5 & 82.5 & 0.25 & 11 & 0.5 \\
& F4 & 82.5 & 0.25 & 11 & 3.0 \\
& Other faults & 82.5 & 0.25 & 11 & 1.0 \\
\hline
\end{tabular}

of GPS, the calculation result reflects the deformation of blocks and faults during this time. Active faults present plastic deformation when they slip. But, during the interval of slip, the locking faults present elastic state. Thus, the faults along which large earthquakes occurred can be considered as being under the plastic state.

Firstly, we try to get the present strain and stress for the Bayan Har block and its peripheral blocks and faults under the constraint of GPS observation. Four cases are designed to investigate the present strain and stress for the Bayan Har block and its peripheral blocks and faults (Table 1). In case 1 , both the blocks and faults are under the elastic state, and none of them gets to the plastic yield. In case 2, F5 is given low yield strength, which would get to plastic state firstly. In case 3, F2 and F5 are given low yield strength; other block and faults are given high yield strength. In case 4, F2, F4, and F5 are given low yield strength. We will compare the calculated results with GPS observation in the interior of the model for each case. Root mean square error (RMSE) would be calculated and the minimum error model would be selected as the optimization model to calculate the present stress and strain for Bayan Har block.

Secondly, we try to get the evolution of strain and stress around Bayan Har block in the future. It is difficult to estimate the actual yield strength. However, under specific boundary conditions and the geometry of fault, the yield strength of faults is corresponding to the earthquake recurrence intervals. Therefore, to investigate the evolution of strain and stress around the Bayan Har block, we give the yield strength for different faults according to the recurrence intervals of earthquakes (case 5) [14, 50-52]. All the blocks are under the elastic state in the calculation.

The elastic modulus and Poisson's ratio are obtained by the seismic velocity and crustal density [53-55]. Plastic parameters are more complicated. The internal friction angle $\phi$ and cohesion $c$ have close relation with lithology, confining
TABLE 2: RMSE for each model.

\begin{tabular}{lccc}
\hline Cases & $\begin{array}{c}\text { East RMSE } \\
(\mathrm{mm} / \mathrm{a})\end{array}$ & $\begin{array}{c}\text { North RMSE } \\
(\mathrm{mm} / \mathrm{a})\end{array}$ & $\begin{array}{c}\text { Magnitude RMSE } \\
(\mathrm{mm} / \mathrm{a})\end{array}$ \\
\hline Case 1 & 3.897 & 2.079 & 4.417 \\
Case 2 & 3.377 & 1.982 & 3.916 \\
Case 3 & 2.813 & 1.920 & 3.406 \\
Case 4 & 2.817 & 2.02 & 3.466 \\
\hline
\end{tabular}

pressure, and strain. In this study, we select them based on the low strain rate test results for marble and sandstone $[56,57]$.

\section{Results}

3.1. Present Deformation around Bayan Har Block. In case 1, we calculate the velocity in one incremental displacement because velocity is the same in every incremental step under elastic state. For other cases, incremental displacement is loaded on the boundary of the model until the faults which have low yield strength get to plastic state. Root mean square errors (RMSE) $[58,59]$ have been calculated for each case (Table 2). By comparing the calculated velocity and GPS observation, we select the optimization case (Figure 3). For case 1, the slip among the blocks is relatively small because there are not plastic faults among them. Actually, large earthquakes occurred along the large strike-slip faults, such as Kunlun Shan fault (F2) and Yushu-Xianshuihe fault (F5), which caused the movement of the blocks. Thus, the fitting is not very well along the large strike-slip faults (Figure 3(a)). That implies that the elastic model cannot be used to explain the deformation around the Bayan Har block. The fitting error is relatively small in case 2 because the Yushu-Xianshuihe fault (F5) is under the plastic state, which makes the block slides with it. But fitting error is relatively large compared to the north of Bayan Har block. The fitting error is the smallest in case 3. That means plastic deformation along the Kunlun Shan fault (F2) and Yushu-Xianshuihe fault (F5) is dominant in the observation interval (1991-2005). East Kunlun Shan fault is the northern boundary of the Bayan Har block. Its rupture has caused several large earthquakes over the past century, including the 1937 Huashixia Ms7.5 earthquake, 1963 Alake Lake Ms7.0 earthquake, and 2001 Kusai lake Ms8.1 earthquake [3, 7, 43,60]. These earthquake have caused significant coseismic surface rupture. YushuXianshuihe fault is the southern boundary of the Bayan Har block. The activation of this fault is very strong. Almost each segment has recorded the occurrence of earthquake that is larger than M7.0 since the documented earthquakes [5, 43, 61-65]. Thus, plastic deformation along the Kunlun Shan fault (F2) and Yushu-Xianshuihe fault (F5) in our model is consistent with the seismic setting in the observation interval (1991-2005). Although 2008 Wenchuan earthquake caused large surface rupture, the Longmen Shan fault (F4 in Figure 2) was locked and presented low strain rate before the earthquake. In the past 1100-1700 years, earthquakes greater than M7.0 were not recorded before Wenchuan earthquake 


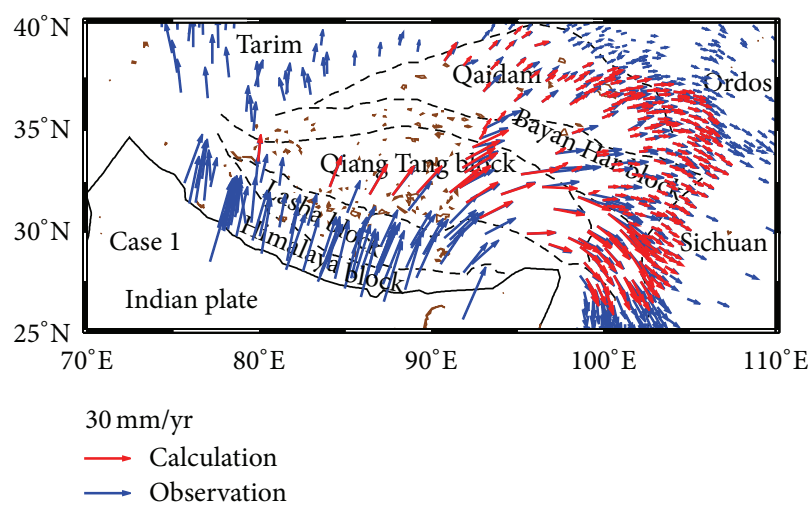

(a)

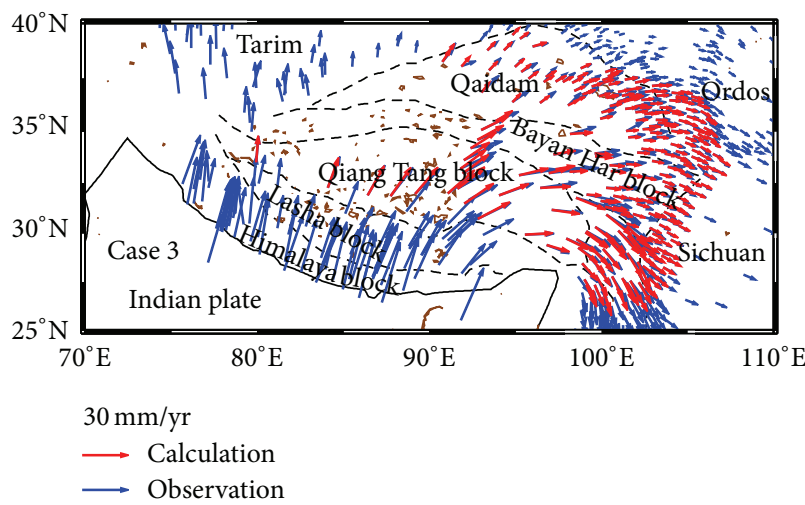

(c)

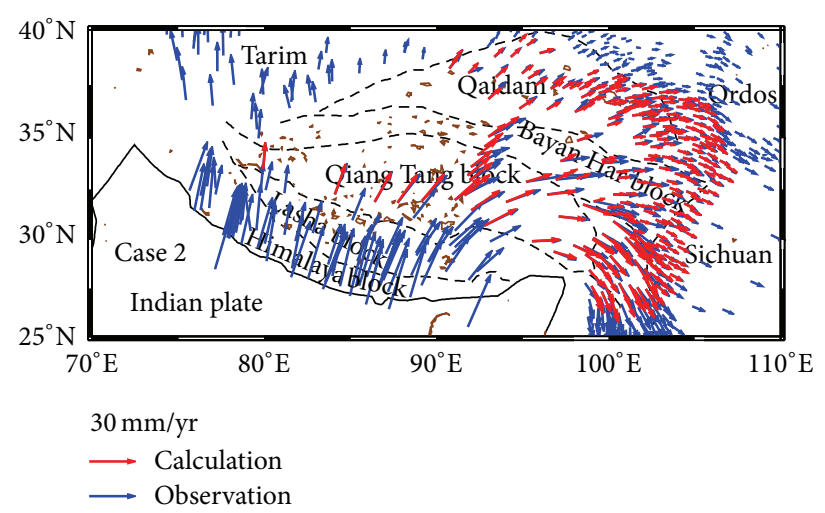

(b)

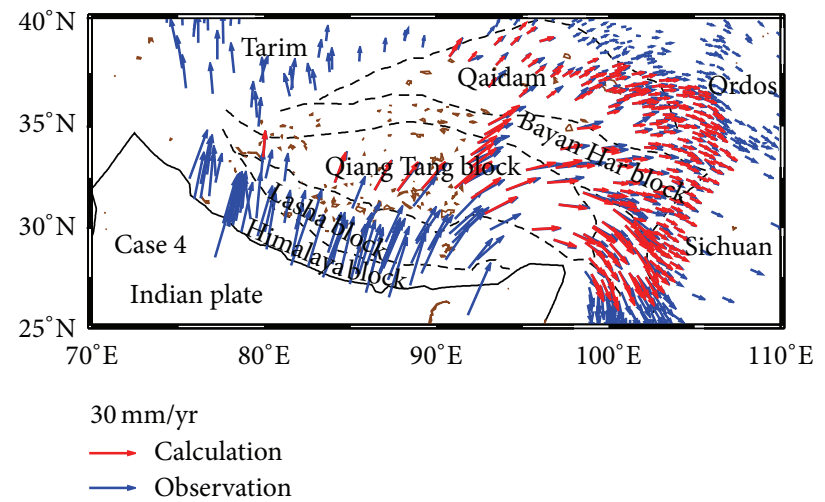

(d)

FIGURE 3: Velocity comparison between calculation and GPS observation for cases 1-4. The calculative velocity in each figure shows the results after 1020 year (1020 time steps) in the elastoplastic state.

along the Longmen Shan fault zone [65-68]. The DongdatanXidatan and Maxin-Maqu segments of the East Kunlun Shan fault (F3 in Figure 2) did not record earthquakes which are larger than M7.0 [65]. The west of Yushu-Xianshuihe fault is the Margaichaka-RolaKangri fault. There were only two Ms7.0 earthquakes occurrence in this segment [5]. Therefore, except for the Kunlun Shan fault and Yushu-Xianshuihe fault, other faults were almost locked or presented elastic state in the observation interval (1991-2005). In case 4, we gave a low yield strength for the Longmen Shan fault (F3). The fitting error is nearly the same as case 3 . This indicates that the effect of a large earthquake on the overall GPS velocity is limited. The result for case 4 may present the deformation of Bayan Har block after the Wenchuan earthquake (Figure 3(d)).

Case 3 has the minimum fitting error. Thus, we select it as the optimization model to calculate the present stress and strain rate for Bayan Har block (Figure 4). In this case, the Kunlun Shan fault and Yushu-Xianshuihe fault have high accumulation strain (Figure 4(b)). Large displacement along these strike-slip faults adjusts the substance movement from the strong Indo-Asian collision [58]. High strain rate along the faults allows the crust to move southeastward in the eastern Tibetan Plateau [69]. In the block interior, the strain rate is relatively uniform and small. Corresponding to the high strain rate, the accumulation stress along the strike-slip faults is relatively low because the plastic yield causes stress drop. The stress directions show that the extension is dominant in the northwest of Bayan Har block (Figure 4(c)), for instance, nearly the westeast extension in the location of 2008 Yutian earthquake. However, compression is dominant along the Longmen Shan fault. This results are consistent with the focal mechanism (Figure 4(d)).

3.2. The Possible Evolution of Stress and Strain around Bayan Har Block. Although there are many factors that influence the deformation results, the evolution of stress and strain for the mainly faults under the present velocity constraint can be investigated with specific assumption. In our model, elastic state implies that the fault is locked and plastic state indicates that the fault is rupture or slip fault. Thus, with the incremental displacement constraint, the faults with different yield strength would enter plastic state gradually. This process would help us learn which fault is easy for the stress accumulation and which is not. Thus, in case 5, we imposed the yield strength for different faults according to the recurrence intervals of the large earthquakes. The values given in the case may not be equal to the real values. But the order by which the faults get to the plastic yield helps us to understand the deformation process. 


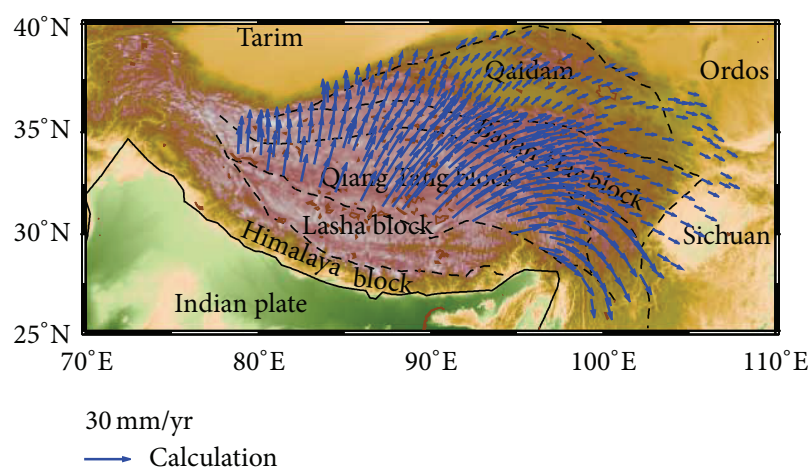

(a)

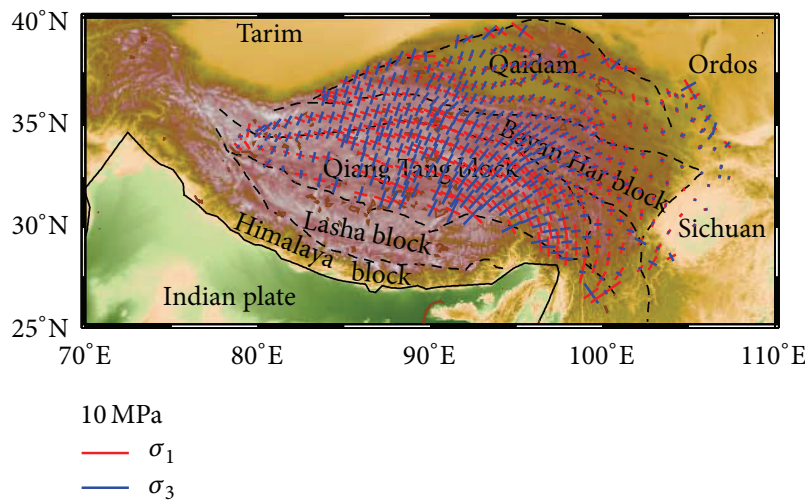

(c)

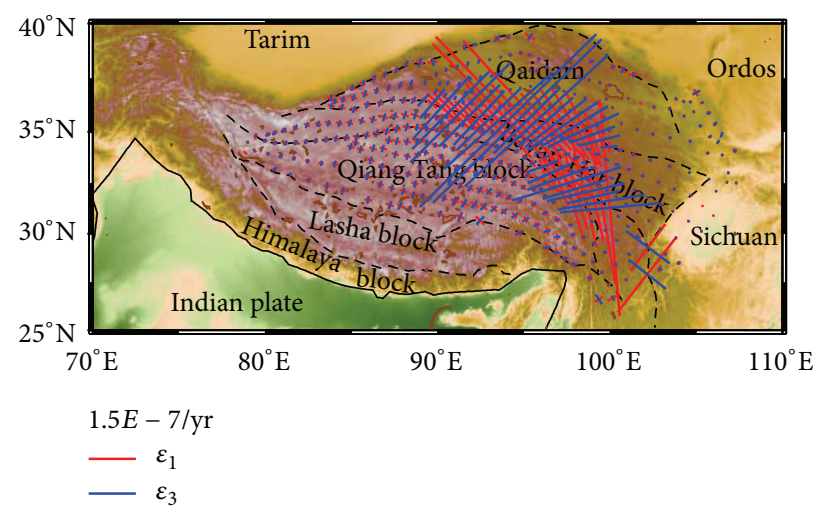

(b)

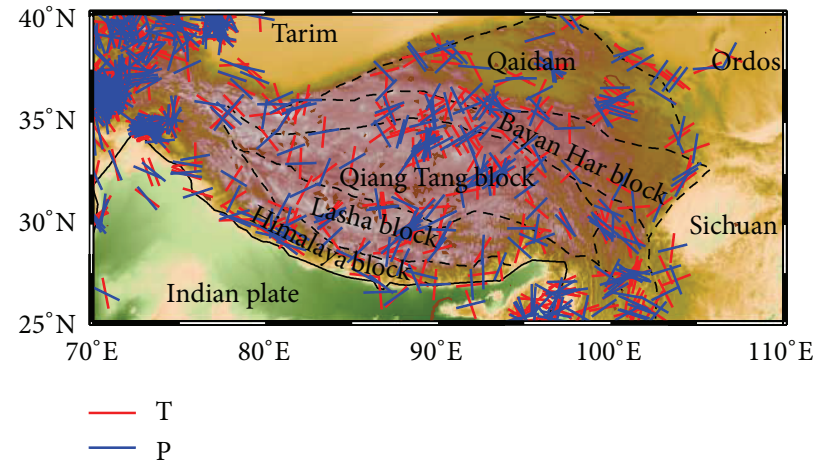

(d)

FIGURE 4: The F2 and F5 faults are under the yield state, the distribution of velocity (a), strain rate (b), and cumulative stress (c) for case 3. Mechanism of earthquakes (d) comes from Harvard CMT catalogue (Mw > 4.0, 1976-2011) (http://www.globalcmt.org/CMTsearch.html). Red and blue lines indicate the tension and pressure axes from the mechanism of earthquake, respectively.

Based on the surface rupture of earthquakes and strain rate, the recurrence intervals for the $M \geq 6.7$ earthquakes along Xianshuihe fault are estimated to be 100-150 years [52]. The recurrence intervals of large earthquakes along the East Kunlun Shan fault, such as 2001 Kusai Lake Ms8.1 earthquake, are 250-350 years $[27,50]$. For the Altyn Tagh fault, the recurrence intervals of earthquakes, such as 2008 Kangxiwa Mw7.4 earthquake, are 370-500 years [50], while, for the Longmen Shan fault, which is characterized slow strain accumulation, such as 2008 Wenchuan earthquake, the recurrence intervals are 3000-6000 years [14, 51]. With these studies, we give a relative values of the yield strength for different faults (case 5 in Table 1). With the constraint of boundary velocity, we will investigate the evolution of stress and strain around the Bayan Har block. But the initial stress is 0 for all the blocks and faults. The order of fault rupture or slip only has relation with the distribution of faults, boundary conditions, and plastic yield strength.

We calculate the effective strain (Figure 5) and effective stress (Figure 6) for case 5 as follows:

$$
\begin{aligned}
& \text { effective strain } \bar{\varepsilon}=\sqrt{\frac{2}{3} \varepsilon_{i j} \varepsilon_{i j}}, \\
& \text { effective stress } \bar{\sigma}=\sqrt{3 J_{2}} .
\end{aligned}
$$

When the fault enters the plastic state, its effective strain is very large, indicating large slip along it (Figure 5). However, the effective stress is decreased, indicating that the faults release the accumulative stress (Figure 6). Stress is accumulated at the end the rupture fault, which caused the strain and stress increase along the surrounding faults. The process of accumulation and transfer of stress lasts until all the faults enter the plastic state. Because of the large yield strength, the blocks remain in the elastic state and have little deformation. The evolution of stress and strain shows that the first fault to get to the plastic state is the Kunlun Shan fault (F2) and Yushu-Xianshuihe fault (F5) because they have low yield strength. Then, the Heishibeihu fault (F1) and MargaichakaRolaKangri faults (F6) get to plastic state. The last yield faults are the East Kunlun Shan fault (F4) and Longmen Shan fault (F3). This order has relation with not only the plastic strength, but also the distribution of faults and boundary conditions. The movement of block depends on the state of surrounding faults. It indicates that the overall movement of Bayan Har block is shown sectionally and periodically.

\section{Discussion and Conclusions}

In this study, the values of yield strength imposed on the blocks and faults are not equivalent to the realistic values 


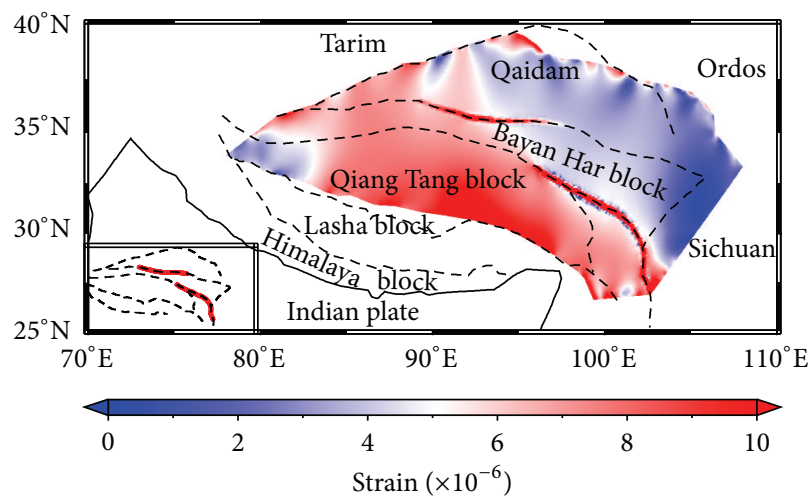

(a)

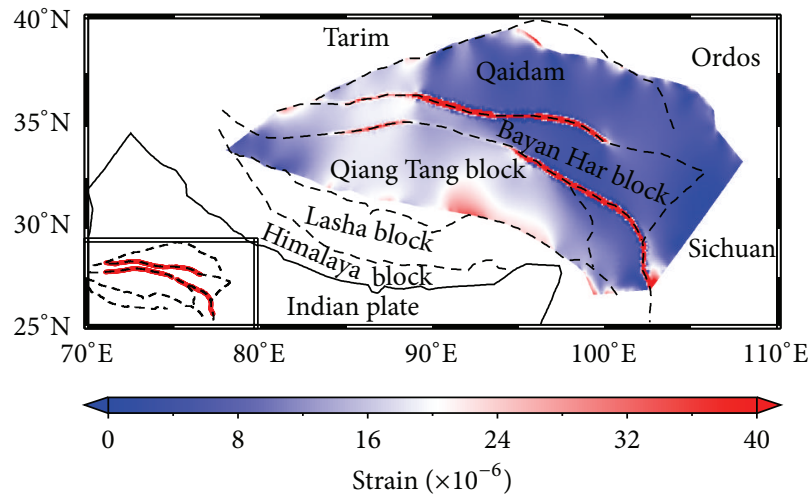

(c)

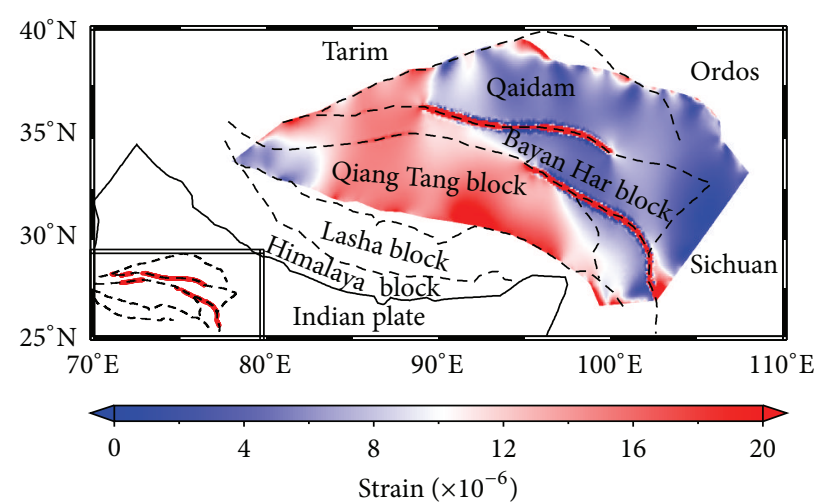

(b)

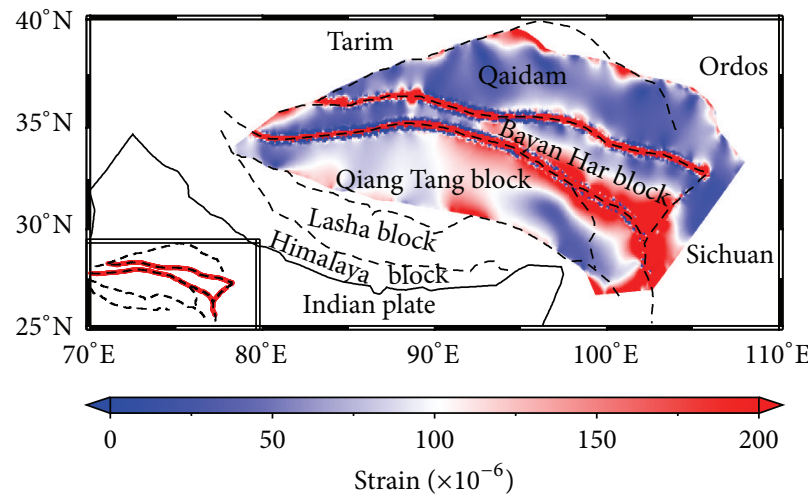

(d)

FiguRE 5: The effect of periphery faults on the accumulative strain of Bayan Har block. The left lower diagram in each figure indicates the state of periphery faults. The red color marked on the fault shows that it is under the yield state. (a)-(d) show the accumulative strain distribution after loading with GPS observation for 264 years, 274 years, 280 years, and 542 years, respectively. The parameters used in this calculation are shown in Table 2 (case 5).

because we cannot obtain the actual value of the faults at the present time. Therefore, if we change the values of them, the last time of entering the plastic state may change accordingly. However, the order of entering the plastic yield state for different major faults around Bayan Har block is almost the same. Actually, slip and locked state are alternatives to the activation of faults. We have not considered the stick-slip of the faults. More complex factors should be considered in the $3 \mathrm{D}$ model, such as heterogeneity, geometric distribution of fault. But the evolution of stress and strain in this $2 \mathrm{D}$ model help us to understand the process of stress and strain accumulation for different faults.

In this study, a 2D plane-stress numerical model was used to investigate the present deformation of Bayan Har block and its possible evolution of stress and strain. Primary conclusions include the following. (a) The elastic model cannot explain the current GPS observation in the Bayan Har block. (b) Presently, plastic deformation is dominant along the East Kunlun fault and Yushu-Xianshuihe fault. It indicates that most of the current strain localization is absorbed by these two faults. (c) If the recurrence intervals of large earthquakes are used to limit the relative yield strength of major faults, the order entering plastic yield state for different major faults around Bayan Har block is as follows. The first to enter the yield state are Yushu-Xianshuihe faults and the middle segment of East Kunlun faults, respectively. Then, the Margaichaka-RolaKangri faults (Mani segment) and Heishibeihu faults would enter the yield state. The last to enter the yield state are the eastern segment of East Kunlun faults and Longmenshan faults, respectively. This indicates that the overall movement of Bayan Har block is shown sectionally and periodically.

\section{Conflict of Interests}

The authors declare that there is no conflict of interests regarding the publication of this paper.

\section{Acknowledgments}

This study is supported by the China Geological Survey (Grant nos. 12120114002401, 12120114002101) and the National Science Foundation of China (Grant no. 41204066). Many the 


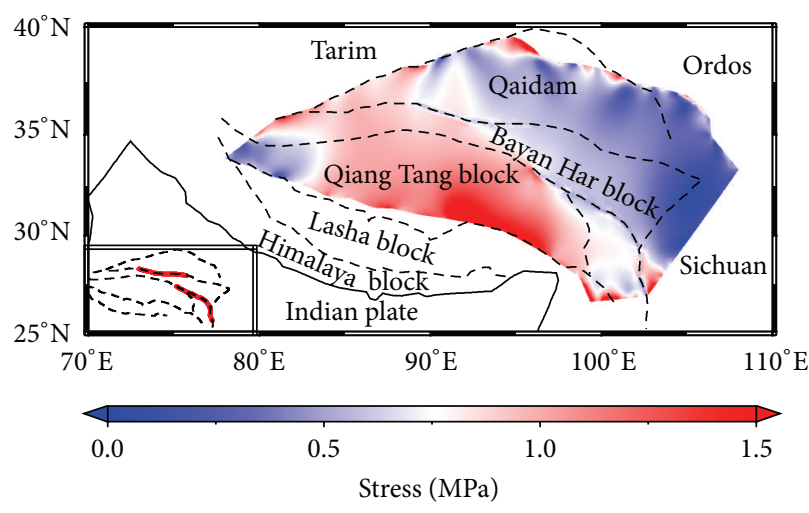

(a)

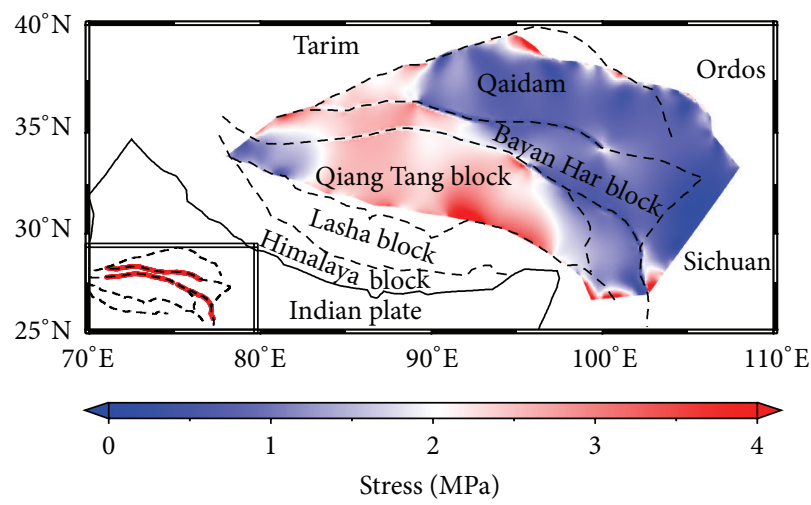

(c)

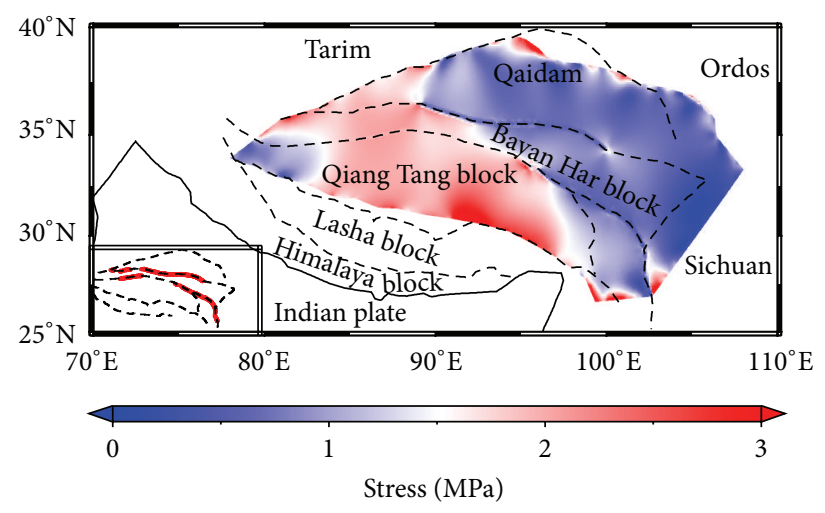

(b)

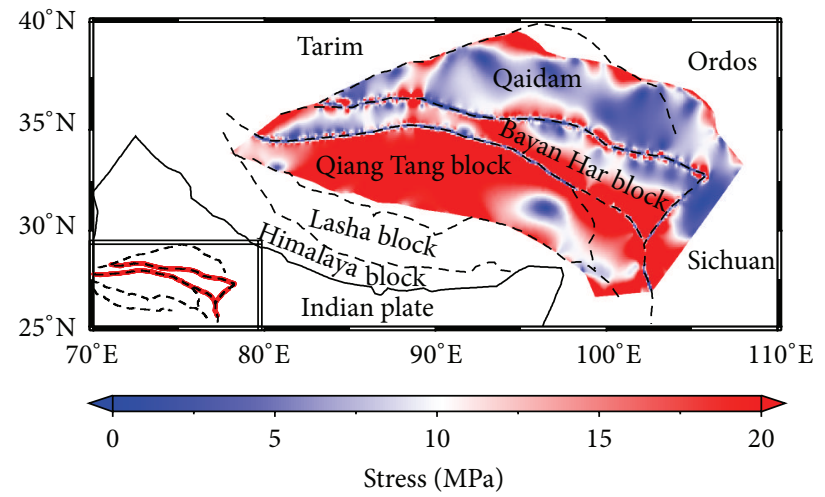

(d)

FIGURE 6: The effect of periphery faults on the accumulative stress of Bayan Har block. The left lower diagram in each figure indicates the state of periphery faults. The red color marked on the fault shows that it is under the yield state. (a)-(d) show the accumulative stress distribution after loading with GPS observation for 264 years, 274 years, 280 years, and 542 years, respectively. The parameters used in this calculation are shown in Table 2 (case 5).

figures are generated by the Generic Mapping Tools (GMT) package [70].

\section{References}

[1] Q. Deng, P. Zhang, Y. Ran, X. Yang, W. Min, and Q. Chu, "Basic characteristics of active tectonics of China," Science in China, Series D: Earth Sciences, vol. 46, no. 4, pp. 356-372, 2003.

[2] P. Zhang, Q. Deng, G. Zhang et al., "Active tectonic blocks and strong earthquakes in the continent of China," Science in China, Series D: Earth Sciences, vol. 46, no. 2, pp. 13-24, 2003.

[3] Q. Deng, X. Gao, G. Chen, and H. Yang, "Recent tectonic activity of Bayankala faul-t block and the Kunlun-Wenchuan earthquake series of the Tibetan Plateau," Earth Science Frontiers, vol. 17, no. 5, pp. 163-178, 2010 (Chinese).

[4] M. Taylor and A. Yin, "Active structures of the HimalayanTibetan orogen and their relationships to earthquake distribution, contemporary strain field, and Cenozoic volcanism," Geosphere, vol. 5, no. 3, pp. 199-214, 2009.

[5] X. Shan, J. Ma, C. Wang, J. Liu, X. Song, and G. Zhang, "Co-seismic ground deformation and source parameters of Mani M7.9 earthquake inferred from spaceborne D-InSAR observation data," Science in China Series D: Earth Sciences, vol. 47, no. 6, pp. 481-488, 2004.
[6] A. Lin, B. Fu, J. Guo et al., "Co-seismic strike-slip and rupture length produced by the 2001 Ms 8.1 central Kunlun earthquake," Science, vol. 296, no. 5575, pp. 2015-2017, 2002.

[7] X. Xu, W. Chen, W. Ma, G. Yu, and G. Chen, "Surface rupture of the Kunlunshan earthquake (Ms 8.1), Northern Tibetan Plateau, China," Seismological Research Letters, vol. 73, no. 6, pp. 884892, 2002.

[8] X.-W. Xu, W.-B. Chen, G.-H. Yu et al., "Characteristic features of the surface ruptures of the Housaihu (Kunlunshan) earthquake (Ms8.1) northern Tibetan plateau, China," Seismology and Geology, vol. 24, no. 1, pp. 1-17, 2002 (Chinese).

[9] J. R. Elliott, R. J. Walters, P. C. England, J. A. Jackson, Z. Li, and B. Parsons, "Extension on the Tibetan plateau: recent normal faulting measured by InSAR and body wave seismology," Geophysical Journal International, vol. 183, no. 2, pp. 503-535, 2010.

[10] X. Shan, G. Zhang, C. Wang et al., "Source characteristics of the Yutian earthquake in 2008 from inversion of the co-seismic deformation field mapped by InSAR," Journal of Asian Earth Sciences, vol. 40, no. 4, pp. 935-942, 2011.

[11] X. Xu, X. Tan, G. Yu et al., "Normal- and oblique-slip of the 2008 Yutian earthquake: evidence for eastward block motion, northern Tibetan Plateau," Tectonophysics, vol. 584, pp. 152-165, 2013. 
[12] J. Liu-Zeng, Z. Zhang, L. Wen et al., "Co-seismic ruptures of the 12 May 2008, Ms 8.0 Wenchuan earthquake, Sichuan: east-west crustal shortening on oblique, parallel thrusts along the eastern edge of Tibet," Earth and Planetary Science Letters, vol. 286, no. 3-4, pp. 355-370, 2009.

[13] X. Xu, X. Wen, G. Yu et al., "Coseismic reverse- and obliqueslip surface faulting generated by the $2008 \mathrm{Mw} 7.9$ Wenchuan earthquake, China," Geology, vol. 37, no. 6, pp. 515-518, 2009.

[14] P.-Z. Zhang, X.-W. Xu, X.-Z. Wen, and Y.-K. Ran, "Slip rates and recurrence intervals of the Longmen Shan active fault zone, and tectonic implications for the mechanism of the May 12 Wenchuan earthquake, 2008, Sichuan, China," Chinese Journal of Geophysics, vol. 51, no. 4, pp. 1066-1073, 2008 (Chinese).

[15] A. Lin, G. Rao, D. Jia, W. Xiaojun, B. Yan, and Z. Ren, "Coseismic strike-slip surface rupture and displacement produced by the 2010 MW 6.9 Yushu earthquake, China, and implications for Tibetan tectonics," Journal of Geodynamics, vol. 52, no. 3-4, pp. 249-259, 2011.

[16] C. Zhou, Z. Wu, C. Nima, J. Li, Y. Jiang, and Y. Liu, "Structural analysis of the co-seismic surface ruptures associated with the Yushu Ms7.1 earthquake, Qinghai Province," Geological Bulletin of China, vol. 33, no. 4, pp. 551-566, 2014 (Chinese).

[17] M. Liu, G. Luo, and H. Wang, "The 2013 Lushan earthquake in China tests hazard assessments," Seismological Research Letters, vol. 85, no. 1, pp. 40-43, 2014.

[18] Z. Wang, J. Su, C. Liu, and X. Cai, "New insights into the generation of the 2013 Lushan Earthquake $\left(M_{s}\right.$ 7.0), China," Journal of Geophysical Research: Solid Earth, vol. 120, no. 5, pp. 3507-3526, 2015.

[19] A. L. Densmore, M. A. Ellis, Y. Li, R. Zhou, G. S. Hancock, and N. Richardson, "Active tectonics of the Beichuan and Pengguan faults at the eastern margin of the Tibetan Plateau," Tectonics, vol. 26, no. 4, 2007.

[20] J. Cheng, J. Liu, W.-J. Gan, and H.-Z. Yu, "Coulomb stress interaction among strong earthquakes around the Bayan Har block since the Manyi earthquake in 1997," Chinese Journal of Geophysics, vol. 54, no. 8, pp. 1997-2010, 2011 (Chinese).

[21] M. Furuya and T. Yasuda, "The 2008 Yutian normal faulting earthquake (Mw 7.1), NW Tibet: non-planar fault modeling and implications for the Karakax Fault," Tectonophysics, vol. 511, no. 3-4, pp. 125-133, 2011.

[22] Y. Li, L. Chen, S. Liu, S. Yang, X. Yang, and G. Zhang, "Coseismic Coulomb stress changes caused by the Mw6.9 Yutian earthquake in 2014 and its correlation to the 2008 Mw7.2 Yutian earthquake," Journal of Asian Earth Sciences, vol. 105, pp. 468-475, 2015.

[23] B. C. Burchfiel, L. H. Royden, R. D. van der Hilst et al., "A geological and geophysical context for the Wenchuan earthquake of 12 May 2008, Sichuan, People's Republic of China," GSA Today, vol. 18, no. 7, pp. 4-11, 2008.

[24] J. Hubbard and J. H. Shaw, "Uplift of the Longmen Shan and Tibetan plateau, and the 2008 Wenchuan $(M=7.9)$ earthquake," Nature, vol. 458, pp. 194-197, 2009.

[25] Y. Li, D. Jia, J. H. Shaw et al., "Structural interpretation of the coseismic faults of the Wenchuan earthquake: threedimensional modeling of the Longmen Shan fold-and-thrust belt," Journal of Geophysical Research: Solid Earth, vol. 115, no. 4, 2010.

[26] Y. Klinger, X. Xu, P. Tapponnier, J. Van der Woerd, C. Lasserre, and G. King, "High-resolution satellite imagery mapping of the surface rupture and slip distribution of the $\mathrm{Mw} \sim 7.8,14$
November 2001 Kokoxili earthquake, Kunlun fault, Northern Tibet, China," Bulletin of the Seismological Society of America, vol. 95, no. 5, pp. 1970-1987, 2005.

[27] H. Li, J. Van der Woerd, P. Tapponnier et al., "Slip rate on the Kunlun fault at Hongshui Gou, and recurrence time of great events comparable to the 14/11/2001, Mw $\sim 7.9$ Kokoxili earthquake," Earth and Planetary Science Letters, vol. 237, no. 1-2, pp. 285-299, 2005.

[28] C. Xie, X. Lei, X. Wu, and X. Hu, "Short- and long-term earthquake triggering along the strike-slip Kunlun fault, China: insights gained from the Ms 8.1 Kunlun earthquake and other modern large earthquakes," Tectonophysics, vol. 617, pp. 114-125, 2014.

[29] P. England, G. Houseman, and L. Sonder, "Length scales for continental deformation in convergent, divergent, and strikeslip Environments: analytical and approximate solutions for a thin viscous sheet model," Journal of Geophysical Research: Solid Earth, vol. 90, no. 5, pp. 3551-3557, 1985.

[30] P. England and D. McKenzie, "A thin viscous sheet model for continental deformation," Geophysical Journal of the Royal Astronomical Society, vol. 70, no. 2, pp. 295-321, 1982.

[31] Y.-J. Sun, S.-W. Dong, T.-Y. Fan, H. Zhang, and Y.-L. Shi, "3D rheological structure of the continental lithosphere beneath China and adjacent regions," Chinese Journal of Geophysics, vol. 56, no. 5, pp. 546-558, 2013.

[32] M. Liu, Y. Yang, S. Stein, and E. Klosko, "Crustal shortening and extension in the central andes: insights from a viscoelastic model," in Plate Boundary Zones, pp. 325-339, American Geophysical Union, 2013.

[33] M. Liu, Y. Yang, S. Stein, Y. Zhu, and J. Engeln, "Crustal shortening in the Andes: why do GPS rates differ from geological rates?" Geophysical Research Letters, vol. 27, no. 18, pp. 30053008, 2000.

[34] J.-P. Avouac and P. Tapponnier, "Kinematic model of active deformation in central Asia," Geophysical Research Letters, vol. 20, no. 10, pp. 895-898, 1993.

[35] P. Tapponnier, X. Zhiqin, F. Roger et al., "Oblique stepwise rise and growth of the tibet plateau," Science, vol. 294, no. 5547, pp. 1671-1677, 2001.

[36] C. Beaumont, R. A. Jamieson, M. H. Nguyen, and B. Lee, "Himalayan tectonics explained by extrusion of a low-viscosity crustal channel coupled to focused surface denudation," Nature, vol. 414, no. 6865, pp. 738-742, 2001.

[37] C. Beaumont, R. A. Jamieson, M. H. Nguyen, and S. Medvedev, "Crustal channel flows: 1 . Numerical models with applications to the tectonics of the Himalayan-Tibetan orogen," Journal of Geophysical Research, vol. 109, no. 6, Article ID B06406, 2004.

[38] P. Fullsack, "An arbitrary Lagrangian-Eulerian formulation for creeping flows and its application in tectonic models," Geophysical Journal International, vol. 120, no. 1, pp. 1-23, 1995.

[39] J. P. Vilotte, M. Daignières, and R. Madariaga, "Numerical modeling of intraplate deformation: simple mechanical models of continental collision," Journal of Geophysical Research, vol. 87, no. 13, pp. 10709-10728, 1982.

[40] J. P. Vilotte, R. Madariaga, M. Daignieres, and O. Zienkiewicz, "Numerical study of continental collision: influence of buoyancy forces and an initial stiff inclusion," Geophysical Journal of the Royal Astronomical Society, vol. 84, no. 2, pp. 279-310, 1986.

[41] T.-Y. Fan, Y.-J. Sun, and Z.-H. Wu, "Numerical modeling analysis of the rotation deformation mechanism of the eastern margin of the Tibetan Plateau," Geological Bulletin of China, vol. 33, no. 4, pp. 497-502, 2014 (Chinese). 
[42] Z. Wu, C. Long, T. Fan et al., "The arc rotational-shear active tectonic system on the southeastern margin of Tibetan Plateau and its dynamic characteristics and mechanism," Geological Bulletin of China, vol. 34, no. 1, pp. 1-31, 2015 (Chinese).

[43] X. Gao and Q. Deng, "Activity analysis of large earthquakes in boundary faults around the Bayankala faulting block," Acta Geologica Sinica, vol. 87, no. 1, pp. 9-19, 2013 (Chinese).

[44] H. Perfettini and J.-P. Avouac, "Stress transfer and strain rate variations during the seismic cycle," Journal of Geophysical Research B: Solid Earth, vol. 109, no. 6, Article ID B06402, 2004.

[45] W.-F. Chen and F. A. Saleeb, Constitutive Equations for Engineering Materials, Elsevier, New York, NY, USA, 1994.

[46] W. Gan, P. Zhang, Z.-K. Shen et al., "Present-day crustal motion within the Tibetan Plateau inferred from GPS measurements," Journal of Geophysical Research: Solid Earth, vol. 112, no. 8, Article ID B08416, 2007.

[47] Z.-K. Shen, J. Lü, M. Wang, and R. Bürgmann, "Contemporary crustal deformation around the southeast borderland of the Tibetan Plateau," Journal of Geophysical Research: Solid Earth, vol. 110, no. 11, Article ID B11409, 2005.

[48] Q. Wang, P.-Z. Zhang, J. T. Freymueller et al., "Present-day crustal deformation in China constrained by global positioning system measurements," Science, vol. 294, no. 5542, pp. 574-577, 2001.

[49] Z. Niu, M. Wang, H. Sun et al., "Contemporary velocity field of crustal movement of Chinese mainland from Global Positioning System measurements," Chinese Science Bulletin, vol. 50, no. 9, pp. 939-941, 2005.

[50] H.-B. Li, J.-L. Si, J.-W. Pan, Z.-L. Qiu, Z.-M. Sun, and J.-L. Pei, "Deformation feature of active fault and recurrence intervals estimation of large earthquake," Geological Bulletin of China, vol. 27, no. 12, pp. 1968-1991, 2008 (Chinese).

[51] C. Liu, B. Zhu, and Y. Shi, "Stress accumulation of the Longmenshan fault and recurrence interval of Wenchuan earthquake based on viscoelasticity simulation," Acta Geologica Sinica, vol. 86, no. 1, pp. 158-169, 2012 (Chinese).

[52] H.-L. Ran and H.-L. He, "Research on the magnitude and recurrence interval of characterized earthquakes with Magnitude > 6.7 along the northwestern portion of the Xianshuihe fault zone in western Sichuan, China," Chinese Journal of Geophysics, vol. 49, no. 1, pp. 153-161, 2006 (Chinese).

[53] M. S. Karplus, W. Zhao, S. L. Klemperer et al., "Injection of Tibetan crust beneath the south Qaidam Basin: evidence from INDEPTH IV wide-angle seismic data," Journal of Geophysical Research: Solid Earth, vol. 116, no. 7, pp. 1-23, 2011.

[54] J. Mechie, W. Zhao, M. S. Karplus et al., "Crustal shear (S) velocity and Poisson's ratio structure along the INDEPTH IV profile in northeast Tibet as derived from wide-angle seismic data," Geophysical Journal International, vol. 191, no. 2, pp. 369384, 2012.

[55] Z. Zhang, Y. Deng, J. Teng et al., "An overview of the crustal structure of the Tibetan plateau after 35 years of deep seismic soundings," Journal of Asian Earth Sciences, vol. 40, no. 4, pp. 977-989, 2011.

[56] J. M. Edmond and M. S. Paterson, "Volume changes during the deformation of rocks at high pressures," International Journal of Rock Mechanics and Mining Sciences \& Geomechanics Abstracts, vol. 9, no. 2, pp. 161-182, 1972.

[57] A. Ord, "Deformation of rock: a pressure-sensitive, dilatant material," Pure and Applied Geophysics, vol. 137, no. 4, pp. 337366, 1991.
[58] J. Cao, Y. Shi, H. Zhang, and H. Wang, "Numerical simulation of GPS observed clockwise rotation around the eastern Himalayan syntax in the Tibetan Plateau," Chinese Science Bulletin, vol. 54, no. 8, pp. 1398-1410, 2009.

[59] B. J. Meade, "Present-day kinematics at the India-Asia collision zone," Geology, vol. 35, no. 1, pp. 81-84, 2007.

[60] S. Wu, G. Li, F. He et al., "Geometry and kinematics in the east segment of the surface rupture zone occurring during the Kunlun earthquake," Geological Bulletin of China, vol. 21, no. 89, pp. 554-561, 2002 (Chinese).

[61] C. R. Allen, Luo Zhuoli, Qian Hong, Wen Xueze, Zhou Huawei, and Huang Weishi, "Field study of a highly active fault zone: the Xianshuihe fault of southwestern China," Geological Society of America Bulletin, vol. 103, no. 9, pp. 1178-1199, 1991.

[62] Q. Deng, "Some thoughts on the Ms8.0 wenchuan," Sichuan Earthquake Seismology and Geology, vol. 30, no. 4, pp. 811-827, 2008 (Chinese).

[63] G.-L. Diao, X.-S. Wang, G.-Y. Gao, X.-H. Nie, and X.-D. Feng, "Tectonic block attribution of Wenchuan and Yushu earthquakes distinguished by focal mechanism type," Chinese Journal of Geophysics, vol. 53, no. 5, pp. 849-854, 2010 (Chinese).

[64] E. Papadimitriou, X. Wen, V. Karakostas, and X. Jin, "Earthquake triggering along the xianshuihe fault zone of western Sichuan, China," Pure and Applied Geophysics, vol. 161, no. 8, pp. 1683-1707, 2004.

[65] X.-Z. Wen, F. Du, P.-Z. Zhang, and F. Long, "Correlation of major earthquake sequences on the northern and eastern boundaries of the Bayan Har block, and its relation to the 2008 Wenchuan earthquake," Chinese Journal of Geophysics, vol. 54, no. 3, pp. 706-716, 2011 (Chinese).

[66] P.-Z. Zhang, X.-Z. Wen, Z.-K. Shen, and J.-H. Chen, "Oblique, high-angle, listric-reverse faulting and associated development of strain: the Wenchuan earthquake of May 12, 2008, Sichuan, China," Annual Review of Earth and Planetary Sciences, vol. 38, pp. 353-382, 2010.

[67] S. Zhu and P. Zhang, "Numeric modeling of the strain accumulation and release of the 2008 Wenchuan, Sichuan, China, earthquake," Bulletin of the Seismological Society of America, vol. 100, no. 5, pp. 2825-2839, 2010.

[68] S. Zhu and P. Zhang, "FEM simulation of interseismic and coseismic deformation associated with the 2008 Wenchuan Earthquake," Tectonophysics, vol. 584, pp. 64-80, 2013.

[69] L. Chen, H. Wang, Y. Ran et al., "The MS 7.1 Yushu earthquake surface rupture and large historical earthquakes on the GarzêYushu Fault," Chinese Science Bulletin, vol. 55, no. 31, pp. 35043509, 2010

[70] P. Wessel and W. H. F. Smith, "New, improved version of generic mapping tools released," Eos, Transactions American Geophysical Union, vol. 79, no. 47, p. 579, 1998. 

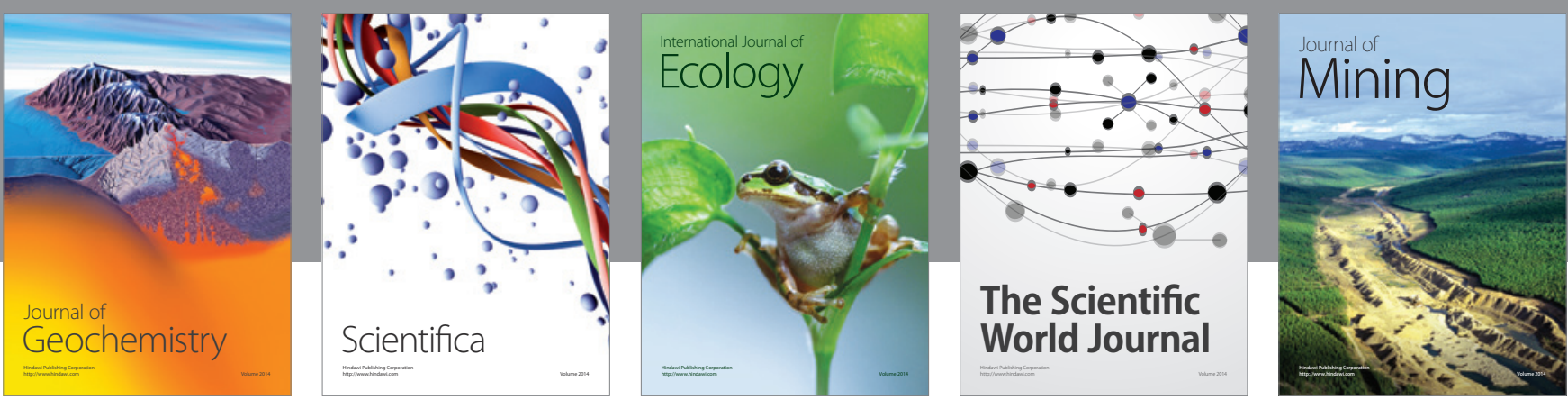

The Scientific World Journal
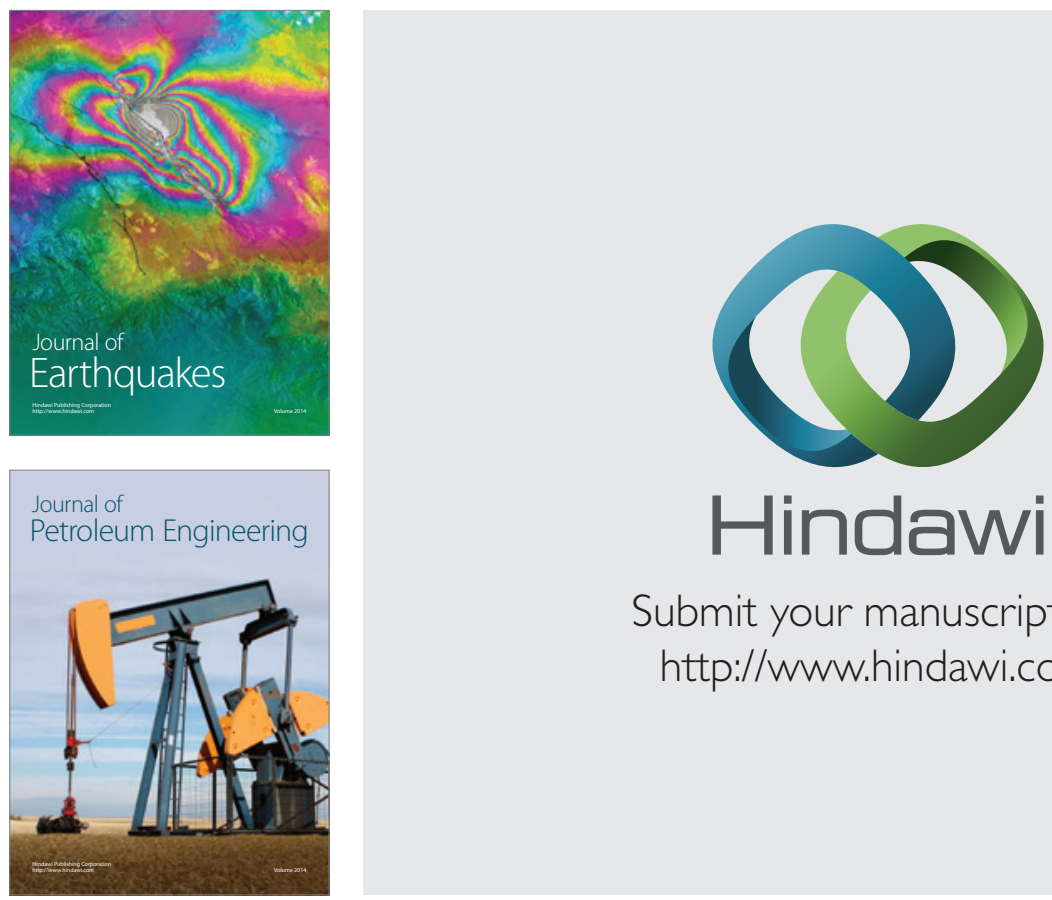

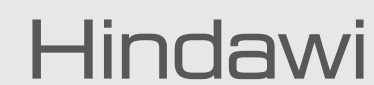

Submit your manuscripts at

http://www.hindawi.com
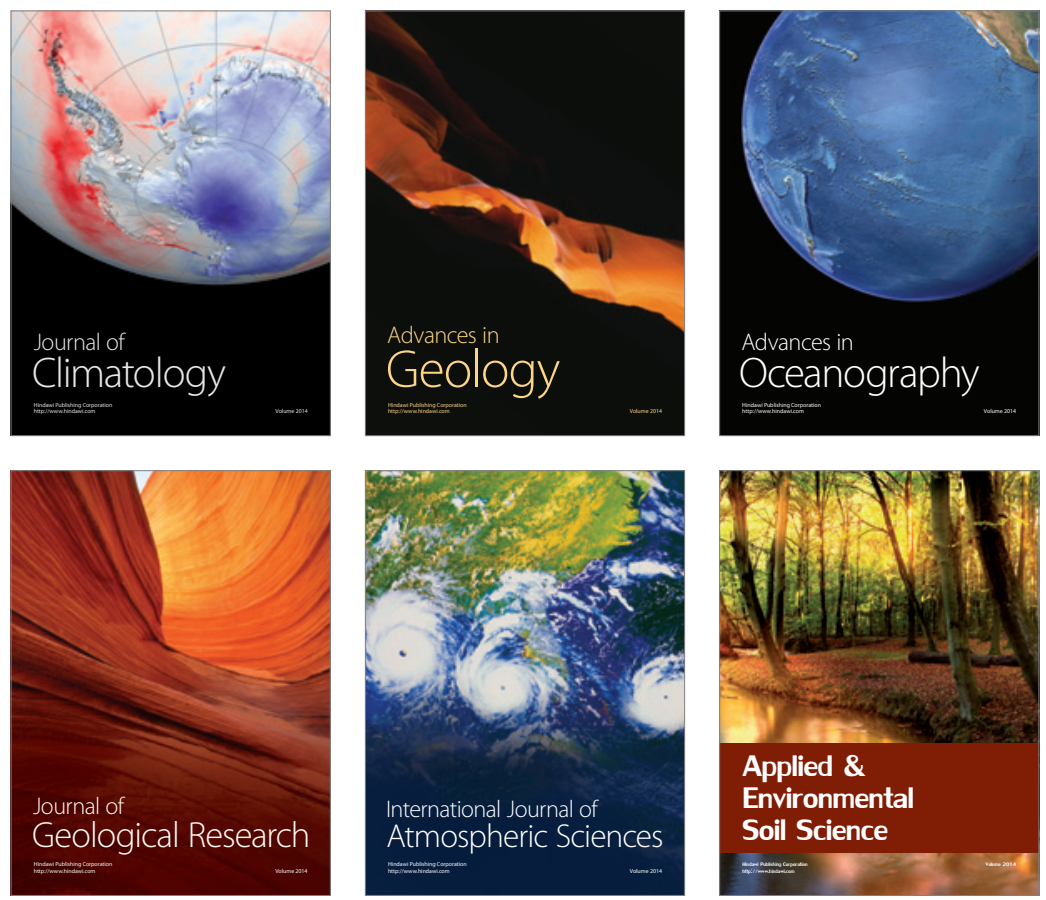
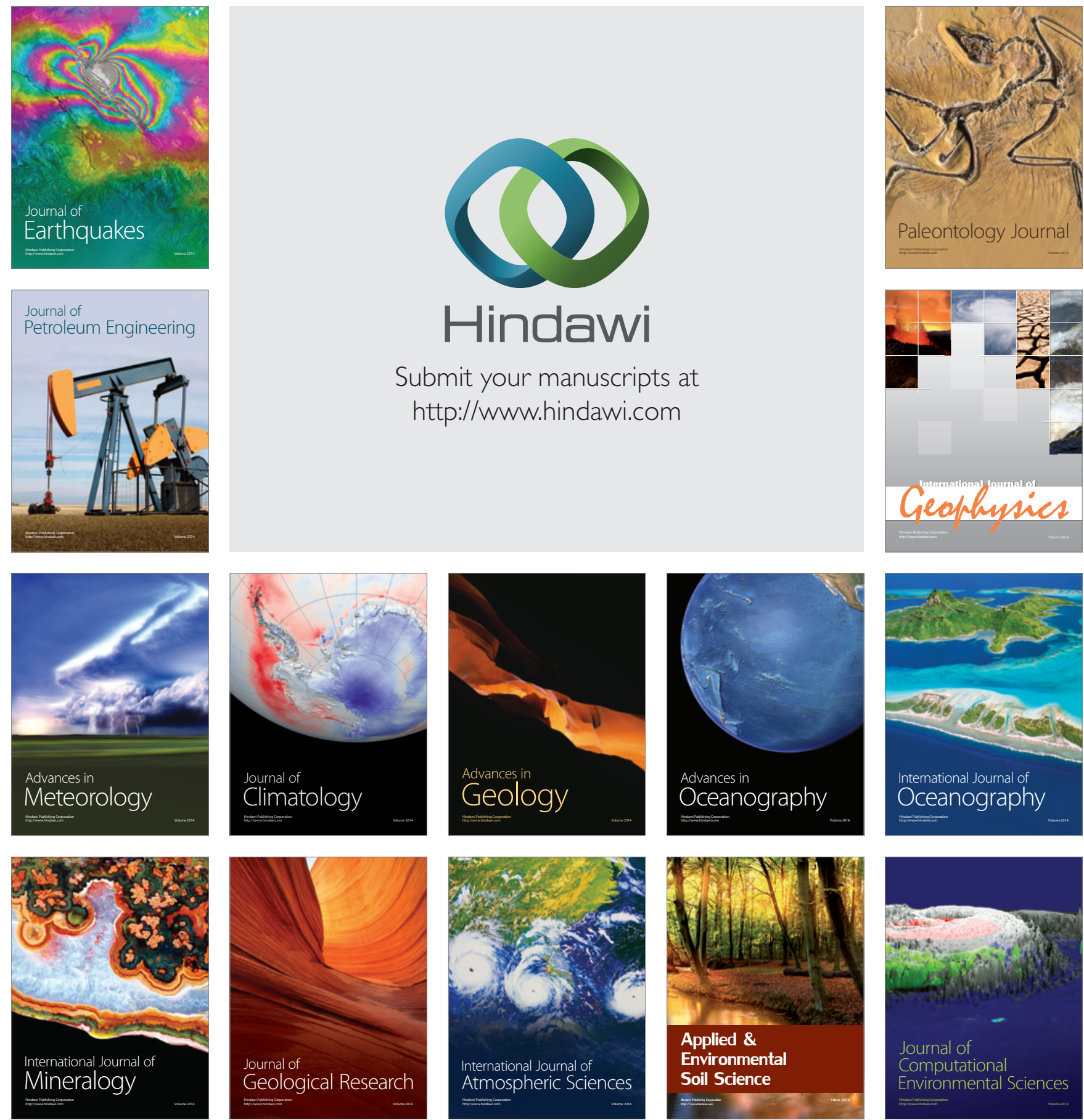